\title{
A concepção educacional de José Pedro Varela (1835-1879)
}

\author{
The educational conception of José Pedro Varela (1845-1879)
}

\section{Andreson Carlos Elias Barbosa}

Doutorando no Programa de Pós-graduação em Educação da Universidade Federal do Pará aceb@oi.com.br

\section{Raimundo Nonato de Pádua Câncio}

\author{
Doutorando no Programa de Pós-graduação em Educação da \\ Universidade Federal do Pará \\ nonatocancio@hotmail.com
}

\section{Sônia Maria da Silva Araújo}

Professora associada da Universidade Federal do Pará ecosufpa@hotmail.com

\begin{abstract}
Resumo: Este artigo aborda a concepção educacional de José Pedro Varela, fundador do sistema educacional uruguaio, contida, principalmente, em suas obras pedagógicas La Educación del Pueblo e La Legislación Escolar. Nestas obras Varela apresenta preciso diagnóstico da educação uruguaia e propõe uma reforma radical, cujos princípios estão pautados na obrigatoriedade, na gratuidade e na secularização do ensino. A partir do estudo realizado, identificamos que Varela conferiu à educação o importante papel de contribuir à superação da ignorância e ao exercício da cidadania, como formas de garantir a sobrevivência do regime democrático, a prosperidade e a felicidade dos homens.
\end{abstract}

Palavras Chaves: Concepção Educacional, América Latina, José Pedro Varela.

\begin{abstract}
This article discusses the educational conception of Jose Pedro Varela, founder of the Uruguayan educational system, contained mainly in his pedagogical works La Educación del Pueblo and La Legislación Escolar. In these books Varela presents an accurate diagnosis of the Uruguayan educational system and proposes a radical reform, the principles of which are compulsory schooling, gratuity and secularization of education. From the analysis, we identified that Varela gave to education an important role in contributing to overcoming ignorance and to the exercise of citizenship, as means of ensuring the survival of democracy, prosperity and happiness of men.
\end{abstract}

Keywords: Educational conception, Latin America, José Pedro Varela. 


\section{Introdução}

Em 1993, a International Bureau of Education (Unesco) publicou uma coleção denominada de Penseurs de l'Éducation (Pensadores da Educação), composta pelos perfis dos cem mais famosos pensadores da educação em todo o mundo. A lista é formada por filósofos, estadistas, políticos, jornalistas, psicólogos, poetas e religiosos que tinham em comum o fato de terem contribuído com suas ideias para a formação de um pensamento educacional a partir de seus países. Dentre estes, constava o nome de José Pedro Varela. ${ }^{1}$

Em 2006, o Ministério da Educação do Brasil instituiu uma comissão técnica composta por representantes da pasta, da Unesco, das universidades e de instituições educacionais como o Instituto Paulo Freire, com o objetivo de elaborar uma lista com os nomes dos principais expoentes da História da Educação mundial. O resultado foi uma lista contendo trinta brasileiros e igual número de autores estrangeiros, dentre os quais novamente figurou Varela. ${ }^{2}$

Em 2011, grupos de pesquisa em História da Educação da América Latina e Caribe desenvolveram um projeto intitulado Educadores na América Latina e CaribeSéculo XVI ao XXI, que resultou em uma obra composta de três importantes publicações. A terceira "analiza la práctica pedagógica y el pensamiento educativo de 18 educadores procedentes de 14 países de América Latina y del Caribe, de la época de la colonia al siglo XIX, articulado com el movimiento científico educativo en el que participó" (SOTO ARANGO et al, 2011: 11). Dentre os educadores destacados, encontra-se, novamente, José Varela.

José Pedro Varela é um daqueles intelectuais da América hispânica cujas ideias instigam-nos, devido ao seu grande impacto causado à educação e a todo um sistema social, ao traçar um diagnóstico da situação de sua época, em fins do século XIX, ao mesmo tempo em que propõe soluções para os problemas educacionais de seu país.

\footnotetext{
${ }^{1}$ Esse foi o primeiro ato de reconhecimento internacional, pois no território uruguaio a importância de Varela como o fundador da escola uruguaia já era conhecida, tanto que em 1918 o governo daquele país inaugurou, numa importante praça localizada no centro da capital, um grande monumento em homenagem a esse homem ilustre.

${ }^{2} \mathrm{O}$ trabalho dessa comissão deu origem a uma coleção de livros acerca desses educadores que foi distribuída às bibliotecas escolares e públicas assim como se encontra disponível no site do Ministério da Educação: <www.mec.gov.br>.
} 
Naquele período, o Uruguai vivia grandes transformações sociais resultantes de uma crise provocada pelo processo de consolidação da independência do país, iniciado em 1825, das disputas políticas entre os partidos colorado e blanco que culminaram na Grande Guerra, conflito que extrapolou uma década, e também pelo avanço da modernização na América Latina, o que causou, dentre outras coisas, intenso êxodo rural.

Segundo Rocchietti, o Uruguai vivenciava um cenário entre guerras e revoltas fratricidas. Por conta disso, o país estava atrasado "em seu desenvolvimento econômico e social em comparação com outras sociedades mais industrializadas e lutava por acompanhar o incipiente, mas irreversível processo de modernização" (2010: 117). Para Varela, diante desta realidade, a educação representava a própria luz, o caminho que poderia levar à democracia e à libertação de um povo (1964a).

José Pedro Varela nasceu em Montevidéu, em 19 de março de 1845, em uma família de comerciantes argentinos, estabelecidos no Uruguai. Foi um importante jornalista e poeta uruguaio "con un buen bagaje cultural”. Seu pai, apesar de comerciante, também era considerado um intelectual e traduziu para o espanhol uma obra didática ${ }^{3}$ francesa do Padre Girard, "que, según parece, fue el primer libro de pedagogía editado en el Río de la Plata" (BRALICH, 2011: 46). Pelo lado materno, a família de Varela também se destacava pela presença de sacerdotes, jornalistas, escritores e poetas, dentre eles, seu tio Bernardo Berro ${ }^{4}$, que se tornou um dos presidentes do Uruguai (1860-1864).

Varela iniciou sua atividade jornalística em Montevidéu, colaborando com artigos para o jornal El Siglo e La Revista Literaria. Posteriormente, atuou em outros periódicos, como o $\mathrm{La} \mathrm{Paz}$, que dirigiu de 1868 a 1873, sendo também um talentoso polemista que se destacava em temas educacionais, culturais e políticos, ao fazer críticas e analisar a situação precária da nação e, nessas circunstâncias, conclamar as autoridades a investirem na educação das massas (DEMARCHI \& RODRIGUEZ, 2010).

A partir de 1876, assumia o cargo de Inspetor da Instrução Pública do Uruguai ${ }^{5}$, mesmo fazendo oposição ao presidente Lorenzo Antonio Inocencio Latorre Jampen (1876-1880), membro do Partido Colorado. Durante seu mandato promoveu a reforma educacional que, por meio de um decreto, estabeleceu o ensino público, gratuito e obrigatório, princípios que sempre defendeu em seus escritos. Devido ao seu falecimento,

\footnotetext{
${ }^{3}$ Com o título La enseñanza de la lengua materna.

${ }^{4}$ Além de importante político uruguaio, Bernardo Prudencio Berro (1799-1868) foi também poeta. Sua atividade literária foi desenvolvida principalmente entre 1824 e 1837 . Nas suas composições classicistas ele abordou temas filosóficos, morais, patrióticos, bem-humorados e bucólicos.

5 À época, esse era o cargo equivalente ao de Ministro da Educação.
} 
em 24 de outubro de 1879, em Montevidéu, não pôde ver sua reforma concluída (ROCCHIETTI, 2010; JARDILINO, 2010).

A trajetória intelectual de Varela é marcada por uma vasta produção, composta por artigos jornalísticos, conferências e relatos de sua atuação na Instrução Pública. Também publicou duas obras de caráter pedagógico, La Educación del Pueblo (1874) e La Legislación Escolar (1876) ${ }^{6}$, escritas em um período em que o Uruguai passava por grande crise econômica, a qual acabou por permitir que o coronel Lorenzo Latorre instalasse o segundo governo ditatorial no país.

Dividida em três partes, La Educación del Pueblo é considerada pelo próprio autor uma espécie de resumo de seu acúmulo de leituras na área da educação (VARELA, 1964a). Na obra ele apresenta sua concepção educacional e discorre sobre a necessidade de uma reforma do sistema educativo uruguaio.

No segundo livro, La Legislación Escolar, Varela não somente demonstra a necessidade de uma reforma radical, mas também sua exequibilidade, apresentando uma proposta estruturada, a qual, posteriormente, tentou colocar em prática, quando se tornou inspetor da Instrução Pública. As reformas varelianas contribuíram significativamente à educação uruguaia, marcando a história desse país.

A partir desses textos é possível identificar que Varela sofreu influências do liberalismo e do positivismo e que também atribuiu à educação o importante papel de ajudar na superação da ignorância e no exercício da cidadania, pois acreditava que um governo democrático só poderia se sustentar por meio de um povo educado, capaz de fazer suas próprias escolhas, principalmente em um regime republicano.

\section{Diagnóstico da educação uruguaia nos fins do século XIX}

Entre o final do século XIX e início do século XX (1870-1910), a República Oriental do Uruguai estava imersa em guerras e disputas que ocasionaram uma profunda crise econômica, política, financeira e social. Nesse período, o país passou por importantes transformações, como: a) o fortalecimento do poder dos bancos internacionais; b) o crescimento demográfico e urbanístico, como resultado da expulsão dos camponeses pelos grandes latifúndios; e c) a afirmação da classe dos comerciantes e do poder estatal.

\footnotetext{
${ }^{6}$ Escrito em 1875, mas somente publicado no ano seguinte.
} 
Essas mudanças, aliadas aos avanços científicos e industriais, proporcionaram o surgimento de novas estruturas econômicas e sociais e, principalmente, quando a imprensa se transformou em uma tecnologia de massa, a partir da utilização de novas técnicas de impressão que permitiam maior qualidade, quantidade e celeridade na produção jornalística, tornaram-na um importante instrumento ideológico e também de contestação política naquele país.

A situação de crise, em contraste com as notícias dos grandes avanços científicos e do progresso das nações desenvolvidas, fez com que muitos homens da América Latina, como Varela, buscassem identificar suas causas na industrialização. Desde muito jovem este se interessou pelos temas relacionados à sociedade de sua época, com especial atenção à educação. O conhecimento acerca da realidade de seu país e as observações feitas durante suas viagens internacionais fizeram com que se engajasse na luta em prol do avanço de sua nação.

Cabe observar que a educação latino-americana na segunda metade do século XIX foi considerada, por grande parte de seus pensadores, atrasada, principalmente no que diz respeito aos fundamentos científicos e aos seus objetivos, já que estes se encontrariam alheios às necessidades sociais (VARELA, 1964a; 1964b). Tanto os conteúdos escolares quanto os métodos de ensino foram praticamente inalterados ao longo dos anos e, portanto, resistiam às ideias de progresso, civilização e desenvolvimento defendidas e operacionalizadas pelas sociedades industrializadas (FARAONE, 1968).

José Pedro Varela cumpriu o importante papel de denunciar a situação educacional precária do Uruguai e o perigo que a falta de reconhecimento da importância da educação promovia no país. Em seus textos, clamava a todos que reconhecem que a educação, "assim como a luz do sol”, deveria chegar a todos sem distinção de raça, sexo ou classe social, "iluminando la conciencia del Pueblo y preparando al niño para ser hombre y al homem para ser ciudadano" (VARELA apud DEMARCHI \& RODRIGUEZ, 1993: 812). Em tom de preocupação, lamentava a situação educacional uruguaia. Para ele, as escolas travavam solitariamente verdadeiras batalhas para "salvarse del inmenso naufragio que las amenaza, con mantenerse de pie en medio a las ruinas que las rodean" (VARELA, 1964a: 12).

Suas críticas eram detalhadas: observou que o ensino se restringia a fazer com que os alunos repetissem o abecedário ou, então, ficassem o dia todo completamente desocupados, “condenando a esas infelices criaturas a permanecer quietas, sentadas 
sobre el duro banco, sin respaldo em que apoyarse, com las piernas colgando, durante las cinco o seis horas de clase". Tais estabelecimentos, que mais pareciam "depósitos de guardar crianças", só podiam causar, segundo ele, total "aversion a la escuela, convertida para ir en lugar de martírio" (VARELA, 1964b: 152).

Mediante tal situação, Varela critica tanto a população quanto os governantes. Os segundos eram criticados por não demonstrarem real interesse pela educação e por usarem-na inadequadamente, como quando deixavam as crianças nas escolas apenas para poderem se dedicar a outras atividades. Varela também salientava que, embora os uruguaios fossem um povo generoso, solidário com os pobres e doentes e até mesmo com as festas públicas e religiosas, não possuíam a mesma disposição quando se tratava de se doar para a causa educacional (1964a). Na percepção do uruguaio, a educação só costumava receber doações “contadas y reducidas, e insignificantes” (VARELA, 1964a: 8), ao contrário de outros países, como os Estados Unidos, cuja população contribuía financeiramente com a causa educacional. Assim, defendia

[...] que esta es una necesidad del Estado, una exigencia de la sociedad y una conveniencia de todos, y sabiendo cuántos y cuan grandes sacrificios es necesario realizar para que a todos lleguen los beneficios de la educación, despréndese, con gusto, de una parte de su fortuna, para alcanzar la realización de ese gran fin (VARELA, 1964a: 9).

No que diz respeito à gestão do governo, Varela critica o descaso demonstrado na priorização do financeiro em detrimento do pedagógico:

¿ir ignora que es entre nosotros matéria de todos los dias, el andar escatimando la instrucción, y sobre todo la buena instrucción, a los niños, para ahorrar algunos centésimos o algunos pesos? ¡qué importa que el texto sea malo, si es barato! ; qué importa que la casa sea estrecha, si el aquiler es reducido! [...]; qué importa, se así se ahorra nalgunos maestros y algunos pesos al fin del año! (1964d: 31).

Da mesma forma, censura a utilização da escola como campo de ação políticopartidária, em que a ação do Estado se tornava uma extensão do partido político que o dirigia. No aspecto geral, isto resultava em administrações públicas que não refletiam os verdadeiros anseios do povo e as suas necessidades. No aspecto mais particular isso se 
refletia nas relações entre escola e comunidade, pois os professores, em aliança com essa prática política, formavam grupos de apoio, fazendo de

[...] cada escuela [era] uma especie de fortaleza donde el maestro respectivo se encontraba atrincherado; nuevos métodos, ideas nuevas, transformaciones, reformas que trataban de realizarse, todo moría, se hundía em los pozos de que la tradición rodeaba la escuela (VARELA apud DEMARCHI \& RODRIGUEZ, 1993:818).

Apesar das críticas, Varela apontava alternativas para os problemas educacionais. Ele descreve como devia ser a relação do povo e do Estado com a educação e o papel que cada um desses agentes precisava assumir diante dessa questão, pois entendia que "la acción individual, por muy decidida que sea, no basta para responder a las múltiples y grandes exigencias de la educación: es necesario el concurso de los ciudadanos y la acción resuelta del Estado" (1964a: 11-23). Assim, compreende que "La familia, primero, debe preparar y vigorizar la enseñanza de la escuela: la sociedad, después, debe desarrollarla y completarla" (VARELA, 1964a: 11-23).

Como podemos observar, para esse intelectual o sistema educacional uruguaio estava muito mal organizado porque não atendia a todos, sendo que a escola pública do país deveria satisfazer às aspirações de todos, independentemente de classe social. Sobre este tema, ele chamava a atenção para a existência de um modelo de educação pública para a população pobre demasiadamente caritativo, que não proporcionava a ascensão social e, por extensão, não colocava no horizonte a superação da sociedade de classes.

Para ele, a educação deveria ser oferecida como um remédio para os males da nação, em que se ensinasse o respeito às leis, se oferecesse o conhecimento do Direito (normas jurídicas) e se incentivasse a prática da virtude e honra (VARELA apud DEMARCHI \& RODRIGUEZ, 1993: 812). Assim, entendia que na escola homens e mulheres receberiam "todos los conocimientos necesarios para responder a lãs múltiples y complicadas exigencias de nuestra epoca" (VARELA, 1964b: 10). Ressalvava, ainda, a importância histórica que esta instituição assumia desde "los albores de la colonia, [cuando] al lado del templo donde los libres pensadores discutían sus creencias, se eleva la escuela donde educan sus futuros hombres [...] Empleando en ellas (las escuelas) cantidades inmensas de inteligencia y de dinero [...]" (VARELA, 1964a: 11-23). 
Todavia, para se chegar a esse ideal era "necesario pues disolver la vieja escuela, derrumbar el viejo edificio, hacer desaparecer completamente la antigua organización [...] en una palabra, produciendo temporalmente el caos para anular la tradición y hacer fácil y posible la reforma proyectada" (VARELA, 1964a: 11-23). Era preciso também reconhecer que, enquanto quesito imprescindível para desencadear mudanças, a escola deveria se pautar por um princípio fundamental: a liberdade.

O cenário crítico apresentado por Varela não consistia apenas em um desabafo do uruguaio, mas na apresentação de proposições no campo da educação. Justificava que os dados educacionais demonstrados em suas conferências e palestras seriam um ponto de partida para importantes proposições à educação. Os membros da Comissão Diretiva da Sociedad de Amigos, que patrocinou esses estudos sobre educação, sob a liderança de Varela, acreditavam que: "En el camino del mejoramiento, es punto previo para todo trabajo serio, la fijación del verdadero estado actual de lo que se pretende mejorar. Antes que nada, necesitamos saber cuál es el estado de la educación en la República: después, veremos lo que debe hacerse y lo que puede hacerse” (VARELA, 1964a: 13).

Assim, "El conocimiento del estado verdadero de la educación en la República era, pues, indispensable para servir de base a las leyes que sobre tan importante materia deben dictarse" (VARELA, 1964a:14). Dentre os objetivos do estudo realizado pela comissão supracitada, destacamos: a) a comprovação da importância da Sociedad de Amigos de la Educación Popular para a nação uruguaia; b) a ratificação de suas boas intenções no que se relacionava à causa educacional; e c) a apresentação de uma proposta fundamentada e exequível para superar o caos demonstrado.

Dessa forma, a Sociedad de Amigos assumia o duplo papel de agente fiscalizador e de propositor do que considerava as soluções para o Uruguai: educação universal, obrigatória, gratuita e laica, e incentivo ao interesse popular pela educação, por meio do surgimento de grupos e/ou instituições “con los mismos propósitos y las mismas aspiraciones" (VARELA, 1964a:11), objetivando promover um verdadeiro movimento em prol da educação, que começava com a apresentação de um diagnóstico da situação educacional no país. Esse trecho aparece no prefácio de La Educación del Pueblo como forma de justificar a publicação e defender a necessidade da nação uruguaia refletir acerca da concepção educacional em vigor.

O livro é o resultado de um investimento de muitos anos, como o próprio autor observa: 
Ahora: por lo que respecta al fondo de este libro, a las ideas en él desarrolladas. La Educación del Pueblo está lejos de ser una improvisación: es el resultado de seis u ocho años de estudios, seguidos con inalterable constancia, al través de todos los acontecimientos de la vida, en el firme y decidido propósito de profundizar, hasta donde me fuese posible, las cuestiones relativas a la educación del pueblo, y de buscar la verdad. Y es esto tanto más cierto, cuanto que ni remotamente aspiro a los honores de la originalidad. Soy de los que creen que la educación es una verdadera ciencia, en cuyo campo sólo puede uno agitarse, con provecho, después de realizar detenidos y meditados estudios (VARELA, 1964a: 7).

Como já dissemos anteriormente, a obra está dividida em três partes. A primeira discute os fins e princípios da educação e apresenta um breve panorama da situação educacional dos países considerados os mais avançados nessa área. A segunda parte, ao relacionar escola e democracia, coloca em questão os princípios essenciais de um sistema educacional democrático. A terceira e última parte, dedicada à escola primária, trata de temas como ensino moral, valorização docente, educação dos adultos etc.

A constatação da Sociedad de Amigos sobre a carência de livros em castelhano que discutissem temas relacionados à educação fora um incentivo para Varela escrever La Educación del Pueblo. Portanto, justifica sua obra pela

[...] esperanza de que, una obra que tratase, con algún detenimiento, las principales cuestiones educacionistas, viniese a llenar un vacío sensible, y a servir eficazmente al progreso de la educación, difundiendo, por una parte, ideas exactas, sobre asunto tan poco conocido entre nosotros por más que a todos nos interese, y, por la otra, estimulando, con el ejemplo, a los hombres ilustrados de nuestro país, para que lo traten con el caudal de luces y de inteligencia que, sin duda, me ha faltado (VARELA, 1964a: 4).

Ao apresentar sua obra à Comissão Diretiva da Sociedad de Amigos, José Pedro Varela deixou registrada, em seu texto, sua pretensão primeira que era a de ser "útil a mi país, propenda al desarrollo y mejoramiento de la educación y estarán cumplidas todas las aspiraciones que me alentaban al escribir [...], aunque no refleje prestigio alguno sobre mi nombre, como escritor público" (1964a: 8). Com a obra, o autor reconhecia a 
necessidade da discussão do tema entre os seus pares, ressaltando sua iniciativa como um esforço em prol da sistematização e do avanço do conhecimento na área.

\section{La concepción general valeriana}

Ter nascido em uma família da alta sociedade uruguaia trouxe a Varela alguns benefícios, principalmente no sentido acadêmico. Entre 1860 a 1866, aprofundou seus estudos em literatura e dedicou-se à aprendizagem de idiomas (francês, inglês e alemão) (ROCCHIETTI, 2010), o que muito contribuiu para o exercício de suas atividades profissionais como jornalista, educador e político.

Esse intenso período de formação culminou com uma viagem que iniciou na Europa e terminou nos Estados Unidos da América, com duração de pouco mais que um ano. Em sua passagem pela França, Varela teve contato com Vitor Hugo ${ }^{7}$. Nos Estados Unidos, conheceu o argentino Domingo Sarmiento, que lhe despertou o interesse pelos temas educacionais (DEMARCHI \& RODRIGUEZ, 2010; BRALICH, 2011). Nesta trajetória, portanto, pôde observar a educação na Europa e nos Estados Unidos da América, à época países considerados de vanguarda nesta área do conhecimento. $\mathrm{O}$ impacto dessa experiência impulsionou-o a fundar - juntamente com outros jovens intelectuais - a Sociedad de Amigos de La Educación Popular ${ }^{8}$, em 1868, tornando-se seu presidente.

Em La Educación del Pueblo o intelectual uruguaio explicita sua concepção educacional. Principalmente no primeiro capítulo, notamos que a educação era compreendida como ciência e, como tal, exigia de seus atores um preparo especial, pautado na dedicação e compromisso. Para Varela, a educação era mais que o cumprimento de uma etapa de escolarização, ou de aquisição de informações: deveria instrumentalizar o sujeito para a superação das dificuldades do cotidiano. Aprender, para o pensador uruguaio, não deveria se limitar ao domínio da leitura e da escrita, mas, acima de tudo, se converter em "um procedimiento que se extiende desde el principio hasta el

\footnotetext{
${ }^{7}$ Victor-Marie Hugo (Besançon, 26/02/1802 - Paris, 22/05/1885) foi um novelista, poeta, dramaturgo, ensaísta, artista, estadista e ativista pelos direitos humanos francês de grande atuação política em seu país. É autor de Les Misérables e de Notre-Dame de Paris, entre diversas outras obras. VICTOR HUGO (s.d.). Wikipedia. A enciclopédia livre. Disponível em: <http://pt.wikipedia.org/wiki/Victor_Hugo>. Acesso em: 15 mar. 2014.

${ }^{8}$ Essa instituição tinha como objetivos a promoção, o avanço e o desenvolvimento da educação popular em todo o território uruguaio e, dentre suas diversas ações, fundou as Bibliotecas populares, tanto na capital quanto no interior do país (ROCCHIETTI, 2010).
} 
fin de la existencia" (VARELA, 1964a: 22), resultante da ação de diversas circunstâncias como a higienização dos espaços de convívio, a suplementação alimentar, a prática de exercícios físicos ao longo da vida e os estímulos sensoriais.

A educação era a mais valiosa herança dos pais para seus filhos. Diferentemente dos bens materiais, que podem facilmente ser perdidos, seus benefícios poderiam ser utilizados "en todas las épocas de la vida, para salvarnos de los crueles naufragios" (VARELA, 1964a: 40).

De caráter humanista, a lógica educacional valeriana tem como perspectiva o homem, sendo este "la única criatura que necesita ser educada: una generación educa a la otra, sin que escapen a esa ley de educación universal, ni aun los pueblos y los individuos que se conservan en estado de la mayor ignorancia" (VARELA, 1964a: 40). Por ser uma ação humana, a educação é uma das necessidades que se sobrepõe aos instintos animais, o que nos insere no contexto da natureza. Ao ser inerentemente humana e resultante das relações que os homens estabelecem entre si, a educação acontece em todo lugar, a todo tempo e em todas as culturas.

No contexto do pensamento republicano uruguaio, a educação é força motriz, sendo considerada o principal meio para o alcance dos objetivos democráticos. Configura-se, portanto, em um “auxiliar poderoso para el desarrollo de una vida íntima, como un llamamiento a um ejercicio, activo y armonioso, de las distintas facultades y poderes com que hemos sido dotados por la Naturaleza" (VARELA, 1964a: 11-23). Somente por meio desta perspectiva os homens adquirem o

[...] poder de pensar, de sentir, de querer, de practicar acciones externas; poder de observar, de razonar, de juzgar; poder de adoptar firmemente buenos fines, y de perseguir eficazmente su realización: poder de gobernarnos a nosotros mismos y de influenciar a los demás: poder de adquirir y de conservar la felicidad (VARELA, 1964a: 25).

Ele ainda afirma que a ignorância do povo, incentivada por certos políticos, produzia apenas "motines, las asonadas, las revueltas constantes, la violación de las leyes, el falseamiento de las instituciones [...] el caos ocultando se bajo el título y las formas aparentes de las instituciones libres" (VARELA, 1964a: 70-71). Para o escritor, a garantia da educação, principalmente às camadas mais populares, produziria a tranquilidade necessária ao Uruguai: "El día en que nuestros gaúchos supieran leer y 
escribir, supieran pensar, nuestras convulsiones políticas desaparecerían quizá. Es por medio de la educación del pueblo que hemos de llegar a la paz, al progreso y a la extinción de los gaúchos" (VARELA apud DEMARCHI \& RODRIGUEZ, 1993: 810).

A educação do povo perpassava a compreensão e o respeito das leis, pois mesmo as "leis boas e modernas" (VARELA, 1964c) eram, muitas vezes, ignoradas pelos mais pobres. Nesse sentido, atribui à República desenvolver cada vez mais as faculdades humanas através da educação, auxiliando o povo no bom exercício da cidadania, virtude cara ao republicanismo:

[...] para hacer respetar la ley, [es necesario] que el pueblo comprenda que es justa; y para que lo compreenda forzoso es que esté educado [...] La mayor parte de nuestras disposiciones políticas están a la altura delas más civilizadas del mundo. ¿Por qué, pues, teniendo leyes buenas vivimos sin embargo en el caos? ¿Por qué las masas de nuestra población ignorantes y atrasadas, ni conocen, ni comprenden, ni respetan la ley? El hombre sólo obedece voluntariamente a lo que cree justo (VARELA, 1964b: 813).

Se, para obedecer às leis, o povo precisava reconhecê-las como justas, fazia-se necessário, segundo Varela, que os legisladores atentassem para os anseios populares em sua elaboração. "Quando se legisla, quando se toca a terra, é necessário levar em consideração as sinuosidades e as asperezas do caminho" (VARELA apud ROCCHIETTI, 2010: 129).

Em relação a isso, quando analisa o sistema educativo uruguaio com base na perspectiva de Varela, Rocchietti (2010) entende que, na visão deste intelectual, a partir da ideia de vida democrática, para o exercício dos direitos e deveres, a educação possui

[...] importância transcendental, que dá a esta condição o caráter imperativo de uma necessidade, [pois] [...] para que o sentimento de igualdade democrática se robusteça no povo não basta decretá-la nas leis; é necessário fazer com que penetre nos costumes, que viva como verdade incontestável no espírito de todos (ROCCHIETTI, 2010: 130).

Para Varela, nas nações com governos democráticos e republicanos todos os cidadãos devem se posicionar em relação aos negócios públicos, considerando principalmente que o futuro político é decidido pelo voto. Em face disto, o autor defende 
ser de extrema importância ilustrar o povo com os conhecimentos necessários às graves matérias (educação, política, segurança nacional etc.), de modo a abordá-las com a competência e para que sejam também exercidos seus direitos políticos. Ainda em relação ao voto popular, o pensador considera que o ato de votar "supone la consciência universal, y la conciencia universal supone y exige la educación universal. Si nella la república desaparece, la democracia se hace imposible" (VARELA, 1964a: 73). Neste sentido, a ausência de políticas democráticas de educação conduziria o Estado republicano à morte, uma vez que o sufrágio universal constituía uma de suas bases estruturais.

Ainda no primeiro capítulo de La Educacióndel Pueblo, Varela observa que sua compreensão sobre educação estava de acordo com a de outros pensadores de sua época (sem citar nenhum em específico), acrescentando que, tanto para ele quanto para os demais, a educação existia apenas se atendesse a uma

[...] triple naturaliza del hombre: sobre su cuerpo, desarrollándolo, com la observación inteligente y sistemada de aquellas benignas leyes que conservan la salud, dan vigor y prolongan la vida; sobre su inteligencia, vigorizando la mente, enriqueciéndola con conocimiento, y cultivando los gustos, que se alían com la virtud, y también sobre sus facultades morales y religiosas, robusteciendola consciência del bien y del deber (VARELA, 1964a: 24).

Somente assim a educação poderia atender a objetivos nobres como a formação para o bem, a retidão, a benevolência, a honradez e a verdade, com vistas ao cumprimento de deveres; o cultivo das inteligências e de mentes fortes; o fortalecimento dos corpos para resistirem às adversidades naturais e sociais. Enfim, à educação caberia “desarrollar y dirigir bien nuestra entera naturaleza; [...] [ella] debe inspirarse en un profundo amor de lo verdadero y observar los procederes para investigarlo" (VARELA, 1964a: :25).

A educação vareliana, nesta perspectiva, geraria grandes benefícios, dentre eles a capacidade de destruir todos os males causados pela ausência de conhecimento, ou seja, a ignorância, origem, no entender de Varela, de "todas las preocupaciones absurdas y los infundados temores, que llenan el espíritu y amargan la vida de los ignorantes, así entre nosotros como en todos los pueblos de la Tierra" (VARELA, 1964a: 33). Para o autor, o fim da ignorância era a solução para todos os males. 
Em relação ao problema da superação da pobreza, mais uma vez, a educação aparecia como meio primordial, pois os homens mais educados eram os que recebiam os melhores ordenados na execução de suas atividades. Isso representava um sinal dos tempos modernos, pois as indústrias valorizavam mais a inteligência e a capacidade mental do que a força bruta:

Los pasmosos descubrimientos de la industria moderna van suprimiendo, a cada día, el empleo de la fuerza bruta del hombre, reemplazando la fuerza animal por la de las máquinas. En todos los ramos de la actividad humana se requiere ya, muy generalmente, al ser inteligente, que, al realizar su trabajo, ejercita, no sólo las fuerzas físicas, sino principalmente las cualidades intelectuales que no poseen, ni poseerán nunca, las máquinas inventadas por el hombre (VARELA, 1964a: 38-39).

No pensamento vareliano, ao melhorar o modo de vida dos indivíduos nas sociedades modernas, a educação promoveria condições mais dignas, sem precedentes na história da humanidade. Ao serem mais educados, os homens também conseguiriam aproveitar melhor o tempo nas atividades mais fugazes. Em outras palavras, ele sugere que a educação prolonga a vida porque

[...] demanda menos esfuerzos para la realización de um trabajo cualquiera, exige menos tiempo y, em consecuencia, si no prolonga materialmente la existencia, hace que puedan realizarse em ella mayores, más proficuos y más perfectos trabajos. La educación, pues, alarga la vida, en cuanto a que nos hace vivir más tiempo, salvándonos de las causas de muerte que entraña la ignorancia, y en cuanto a que exigiéndonos menos tiempo para la realización de nuestras necesidades primordiales, nos habilita para satisfacer cumplidamente otros deseos, otras aspiraciones, más elevadas y más fecundas, que incuba y fortifica en el espíritu del hombre, el alimento nutritivo de la educación (VARELA, 1964a: 43-44).

Por tudo isso, Varela também acredita que a educação é capaz de ampliar tanto a qualidade de vida quanto a própria felicidade dos que a detém, pois, segundo ele, ao destruir os males causados pela ignorância, favorece a prosperidade 
O homem que recebe uma educação satisfatória, denominado de "homem ilustrado", pode ser mais feliz do que aquele que permanece na ignorância, pois, enquanto o homem ignorante "no tiene idea del modo como la inteligência puede ser iluminada y desarrollada por la educacion" (VARELA, 1964a: 46). Por essa ótica, o ignorante permanecerá preso às

[...] preocupaciones más absurdas, del temor a los espectros, a los maleficios, a los seres sobrenaturales, encerrado en un círculo estrecho, ahogado por la atmósfera asfixiante del más degradante materialismo, el hombre ignorante cruza la vida como una sombra, sin dejar una huella de su pasaje por el mundo, y sin que una sola alegría verdadera lo compense de sus temores, de su trabajo y de su miseria (VARELA, 1964a: 47).

O homem ilustrado, ao contrário, percebe o mundo que o cerca de forma completamente diversa, usando como filtro as diversas ideias adquiridas pelas leituras e reflexões e sendo, por conseguinte, capaz de adentrar "en un nuevo mundo, rico en escenas, objetos y movimientos que el hombre ignorante no concibe siquiera" (VARELA, 1964a: 47).

Portanto, se a educação é capaz de produzir tantos benefícios e vantagens ao indivíduo, isoladamente, esse mesmo indivíduo transformado pela educação pode contribuir para a sociedade na qual está inserido. À "medida que la educación se difunde, mejoran las condiciones generales de la sociedad, se aminoran los crímenes y los vicios y aumenta la prosperidad, la fortuna y el poder de las naciones" (VARELA, 1964a: 50). Somente uma nação formada pelo homem ilustrado pode ser feliz, próspera e poderosa.

$\mathrm{Na}$ obra, Varela apresenta dados estatísticos coletados em suas viagens internacionais para demonstrar que as nações que mais investiram em educação tiveram a redução proporcional das taxas de criminalidade, o que, para ele, só comprovava que "la educación, purificando la conciencia individual, es la barrera más poderosa que puede oponerse al desborde de las malas pasiones, que engendran el crimen [...] [posto que] la criminalidad está en relación directa con la ignorancia e inversa con la ilustración del individuo (1964a: 59)

A educação idealizada por José Pedro Varela tinha como produto final o homem educado, ou seja, aquele com a "habilidad de poner, en cualquier emergencia, sus poderes mentales en vigoroso ejercicio, para realizar el objeto que se propone: o, en 
otras palabras, mientras que no se halla en aptitud de obrar conscientemente en todas las emergencias de su vida" (1964a: 26). Esse homem forjado pela luz da educação, tão necessária e vital quanto a luz do sol, como escreveu o intelectual, e que a educação colocara em um nível superior aos demais homens (ignorantes), seria o agente impulsionador do progresso nacional e mantenedor do regime democrático.

Com efeito, por todos os benefícios e vantagens apresentados em suas obras pedagógicas, notadamente em La Educación del Pueblo, Varela defendia que a educação deveria ser disponibilizada aos cidadãos de todas as classes: estes, ao serem educados, se tornariam úteis ao progresso e ao desenvolvimento da República do Uruguai (1964c). Nesse contexto, a escola assumia grande importância, já que seria o lugar onde ocorreria a ilustração tão desejada (CARREÑO RIVERO, 2010).

\section{Considerações finais}

No final do século XIX a República do Uruguai vivenciou guerras e intensas disputas que acarretaram grave crise econômica, política, financeira e social. Tais problemas também favoreceram, de certo modo, o surgimento de novas estruturas econômicas e sociais, como formas alternativas de enfrentar as dificuldades oriundas desse processo, favorecendo o avanço científico, industrial, mas também criando condições para a instalação de uma ditadura.

Foi neste contexto que José Pedro Varela escreveu La Educación del Pueblo (1874) e La Legislación Escolar (1876), suas conhecidas obras pedagógicas que delinearam o pensamento educacional de uma época. Nesses textos o autor denuncia o divórcio entre as formas político-jurídicas e a realidade social, assim como a falsidade dos discursos, tanto da oposição quanto do poder estatal. O intelectual também apresenta ideias revolucionárias sobre a educação, cujas fontes de inspiração foram suas viagens internacionais e, principalmente, seu investimento nas leituras acerca da mesma temática.

Enfim, suas ideias podem ser sintetizadas da seguinte forma: a educação deveria atingir a todas as pessoas, sem nenhum tipo de distinção. Para tal fim, a educação seria obrigatória, gratuita e laica, de modo a se eliminar a ignorância e as superstições. Quanto à gestão educacional e a administração dos sistemas de ensino, Varela acreditava que deveriam ser o mais descentralizadas possíveis, de forma que tanto o Estado quanto a sociedade assumissem um compromisso com a causa educacional. 
Defendia a criação das escolas normais que oferecessem ensino profissionalizado, principalmente às mulheres, às quais deveriam ser abertas as portas da docência, das funções públicas e também das atividades comerciais. Assim estas seriam mais úteis à sociedade e enriqueceriam o espírito pela dedicação a questões mais elevadas que as habilidades de corte e costura.

A evocação ao modelo educacional alemão, que atribuiu grande importância aos jardins de infância como instrumento que permitia que a educação chegasse a todas as crianças, é uma questão central para esse intelectual, uma vez que seu principal objetivo era formar cidadãos úteis, laboriosos e hábeis para o trabalho.

A educação foi concebida como uma ciência rigorosa que exigia de seus protagonistas todo o empenho na realização de estudos na área. Mais do que aprender a ler e a escrever, a simples integralização de uma etapa de escolarização e/ou o acumúlo de determinadas informações e conhecimentos, a educação era um processo que acontecia em todo o tempo e lugar, por toda a vida. Por isso, era a maior herança que uma geração poderia legar à outra; um bem que poderia garantir "a sobrevivência da humanidade" (VARELA, 1964a).

Embora tivesse clareza de que a educação acontecia em todos os lugares, inclusive entre as comunidades ditas selvagens, Varela defendia que somente entre os civilizados esse aprendizado tinha o objetivo de fazer o homem forte e feliz, desenvolvendo suas forças fisicas, morais e intelectuais, com vistas ao bem social.

Ele também acreditava que a educação era a força que movia o republicanismo, pelo seu potencial de auxiliar o povo a compreender as leis e, por consequência, respeitálas. Por isso, ela seria capaz de formar as gerações futuras e garantir o alcance dos fins democráticos, propostos por esse regime. Assim, a partir de seu potencial, a educação poderia desenvolver as faculdades mentais, e os regimes democráticos formariam cidadãos para o direito e a obrigação de se posicionarem quanto aos negócios públicos que, assim, estariam mais preparados para combater os regimes totalitários.

Para esse intelectual, ao formar o homem para o bem e retidão, a educação também o aperfeiçoaria para o cumprimento de seus deveres consigo mesmo e com sua nação, o que proporcionava grandes benefícios individuais e coletivos. Portanto, vencida a ignorância, o homem era finalmente "iluminado", passando a compreender o mundo de forma mais racional e lógica, desenvolvendo sua capacidade mental, com melhor aproveitamento de seu tempo de trabalho e de lazer. 
Com a sua qualidade de vida ampliada, que incluiria práticas mais contemplativas e refinadas, a humanidade rumaria à verdadeira felicidade e, portanto, seria capaz de perceber o mundo de forma completamente diversa da do homem ignorante.

José Pedro Varela teve destaque entre os mais importantes educadores da América Latina e do mundo por uma visão iluminista de educação. Dentre seus méritos está o de ter interpretado de forma inovadora, para aquele momento histórico, as necessidades de uma sociedade que enfrentava o processo de modernização e de grandes mudanças.

\section{Fontes}

VARELA, José Pedro (1964a). Obras pedagógicas: la educación del Pueblo. Tomo I. Coleção Clásicos Uruguayos, vol. 49. Ministerio de Instruccion Pública y Prevision Social/Biblioteca Artigas: Montevideo. Disponível em: <http://www.artigas.org.uy/bibliotecas/cu/049.\%200bras\%20pedagogicas/Libro.p df >. Acesso em: 28 dez. 2013.

(1964b). Obras pedagógicas: la educación del Pueblo. Tomo II. Coleção Clásicos Uruguayos, vol.50. Ministerio de Instruccion Pública y Prevision Social/Biblioteca Artigas: Montevideo. Disponível em: <http://www.artigas.org.uy/bibliotecas/cu/050.\%20Obras\%20pedagogicas/index.p hp?id=203>. Acesso em: 28 dez. 2013.

(1964c). Obras pedagógicas: la legislación escolar. Tomo II. Coleção Clásicos Uruguayos, vol.52. Ministerio de Instruccion Pública y Prevision Social/Biblioteca Artigas: Montevideo. Disponível em: <http://www.artigas.org.uy/bibliotecas/cu/052.\%200bras\%20pedagogicas/index.p hp?id=204 >. Acesso em: 28 dez. 2013.

(1964d). Obras pedagógicas: la legislación escolar. Tomo II. Coleção Clásicos Uruguayos, vol .52. Ministerio de Instruccion Pública y Prevision Social/Biblioteca Artigas: Montevideo. Disponível em: $<$ http://www.artigas.org.uy/bibliotecas/cu/052.\%20Obras\%20pedagogicas/index.p hp?id=204 >. Acesso em: 28 dez. 2013.

\section{Referências Bibliográficas}

BRALICH, Jorge (2011). José Pedro Varela y la gestación de la escuela uruguaya. Revista Historia de la Educación Latinoamericana. vol. 13, n.17, pp. 43-70, jul./dic. Disponível em: <http://www.redalyc.org/pdf/869/86922615003.pdf.>._Acesso em: 15 fev. 2014.

CARREÑO RIVERO, Miryam (2010). El pensamiento pedagógico de José Pedro Varela y su decisiva influencia em la construcción del sistema educativo uruguayo. Bordón. Madrid, vol. 62, n. 2, pp.53-66. Disponível em: $<$ http://redined.mecd.gob.es/xmlui/handle/11162/37225?show=full $>$. Acesso em: 13 mar. 2014. 
DEMARCHI, Marta \& RODRIGUEZ, Hugo (1993). José Pedro Varela, 1845-1879. Perspectivas: Revista Trimestral de Educación Comparada. Paris, UNESCO: Oficina Internacional de Educación, vol. XXIII, n. 3-4, pp. 808-821. Disponível em: <http://www.ibe.unesco.org/publications/ThinkersPdf/varelas.PDF>. Acesso em: 01 jan. 2014.

FARAONE, Roque (1968). Varela: la conciencia cultural. Enciclopedia Uruguaya. Montevideo, $\quad$ n. 23. Disponível em: <http://www.periodicas.edu.uy/o/Enciclopedia_uruguaya/pdfs/Enciclopedia_urug uaya_23.pdf.> Acesso em: 18 fev. 2014.

JARDILINO, José Rubens Lima (2010). O Brasil e o Uruguai de Varela: caminhos cruzados. In: DEMARCHI, Marta \& RODRIGUEZ, Hugo (Orgs.). José Pedro Varela. Coleção Educadores. Brasília: MEC; Recife: Fundação Joaquim Nabuco; Editora Massangana, pp. 37-48.

JARDILINO, José Rubens Lima \& LOPES, Leandro de Proença (2011). Sarmiento y Varela: caminhos de cruces en la educación del conosur em el siglo XIX. In: SOTO ARANGO, Diana et al. (Orgs.). Educadores latino americanos y del Caribe de la colonia al siglo XIX. Tomo III. COLCIENCIAS, DIN, RUDECOLOMBIA, SHELA-HISULA, pp. 123-144. Disponível em: <http://www.saber.ula.ve/bitstream/123456789/33452/1/educadores_xix_xx.pdf>. Acesso em: 10 fev. 2014.

ROCCHIETTI, Marcos (2010). José Pedro Varela: a construção de um sistema educativo nacional, autônomo e igualitário para um Uruguai democrático. In: STRECK, Danilo R. (Org.). Fontes da pedagogia latino-americana: uma antologia. Belo Horizonte: Autêntica, pp. 117-133.

SOTO ARANGO, Diana et al (Orgs.) (2011). Educadores latino americanos y del Caribe de la colonia al siglo XIX. Tomo III. COLCIENCIAS, DIN, RUDE COLOMBIA, SHELA- HISULA. Disponível em: <http://www.saber.ula.ve/bitstream/123456789/33452/1/educadores_xix_xx.pdf>. Acesso em 10 de fev. 2014.

VICTOR HUGO (s.d.). Wikipedia. A enciclopédia livre. Disponível em: <http://pt.wikipedia.org/wiki/Victor_Hugo>. Acesso em: 15 mar. 2014.

Artigo recebido em 31 de março de 2015.

Aprovado em 10 de junho de 2015.

DOI: $10.12957 /$ intellectus.2015.18795 